\title{
Design of Centralized Remote-reading Meter System and Intelligent Network Water Meter
}

\author{
Chuanfeng Li \\ School of Computer and Information Engineering \\ Luoyang Institute of Science and Technology \\ Luoyang, China \\ lichuanfeng@sina.com
}

\author{
Wenguang Diao \\ School of Computer and Information Engineering \\ Luoyang Institute of Science and Technology \\ Luoyang, China \\ litdwg@gmail.com
}

\author{
Chen $\mathrm{Li}$ \\ School of Computer and Information Engineering \\ Luoyang Institute of Science and Technology \\ Luoyang, China \\ leilacoffee@163.com \\ Shuran Zhang \\ School of Computer and Information Engineering \\ Luoyang Institute of Science and Technology \\ Luoyang, China \\ zhangsr9@163.com
}

\begin{abstract}
This paper describes a design to develop a centralized remote-reading meter system which used to overcome shortcomings of the traditional manpower-based reading meter. The system is designed from the host computer, network meter and concentrator three parts. Concentrator is connected to the host computer, so remote meter could be read, monitored and managed by the host computer. The host computer consists of client, server, data service and database, developed by $C \#$ language and SQL Server. The network water meter is based on STC89C52RC microcontroller sending data to the concentrator through 485 bus. The concentrator taking ARM9 and Linux as the core, read meter data by 485 bus, and send data to server through Ethernet. The test results show that the remotereading meter system is accurate, simple, real-time, secure, reliable, and easy to application.
\end{abstract}

Keywords- remote system; network water meter; concentrator; ARM9; Linux

\section{INTRODUCTION}

At present, reading data of residents' ammeter, water meter and gas meter is achieved by manpower. Reading meter people should take time to check meters from door to door every month, which consumes a lot of manpower, material resources, time-consuming and low accurate. To solve this, the computer-based reading meter system is used to replace manpower-based system. Remote reading meter system using intelligent information management can be put into use in residential, apartment intelligent management.

Study on automatic reading meter technology abroad may be started in the 1970 s, after decades of development, the technology is relatively mature, and has been widely used. In China, the development of remote automatic reading meter system started later than abroad, the traditional manual reading meter system is still widely used, which create a big potential market especially remote automatic reading meter technology developing rapidly, so automatic reading meter technology will gradually replace the traditional reading meter ${ }^{[1-4]}$
The system consists of software and hardware components, uses technologies such as embedded technology, network communication, multitask and so on. The system consists of the host computer, concentrator and network meter. Host computer is $\mathrm{C} / \mathrm{S}$ structure, using multi-threading, WCF and other technologies, is responsible for data analysis, water monitoring and management. Concentrator using embedded technology is responsible for data receiving and forwarding ${ }^{[5]}$. Network meter using SCM technology is responsible for water flow data reading and forwarding. The system is mainly used for residential, dormitory and other occasion's intelligent management, so property staff gets a real-time ${ }^{[6,7]}$.

Chapter II is mainly to analyze the system and draw a general framework map, and chapter III is mainly to analyze the specific design of host computer, set forth the specific function, the data dictionary, stored procedures and so on. Chapter IV analyzes the particular design of the concentrator and describes related technologies such as TCP, multithreading, and gives the schematic diagram of the concentrator and the associated flow chart. Chapter V is mainly analyzes specific network meter design, summarizes the specific methods of system testing, and test results. Finally, gives conclusions and future directions for improvement.

\section{SySTEM STRUCTURE DESIGN}

The system consists of a host computer, concentrators, and network meters three major components. Meter using STC89C52 microcontroller reads the resident's actual water consumption at regular time, fulfills data collection, storage, transmission and other tasks. Concentrator using S3C2440 microprocessor, which has a clock speed up to $400 \mathrm{MHz}$, is responsible for data forwarding and storage. Host computer using $\mathrm{C} / \mathrm{S}$ structure design, consists of server, client, data service and database. When reading meter data is required, host computer send commands to the concentrator via Ethernet, the concentrator will analyze data and send codes to meters connected through 485 bus, which check received codes with inside codes, send water 
usage data to concentrator through 485 bus if codes received is consistent with inside $\operatorname{codes}^{[8]}$. General framework is shown in Fig. 1 .

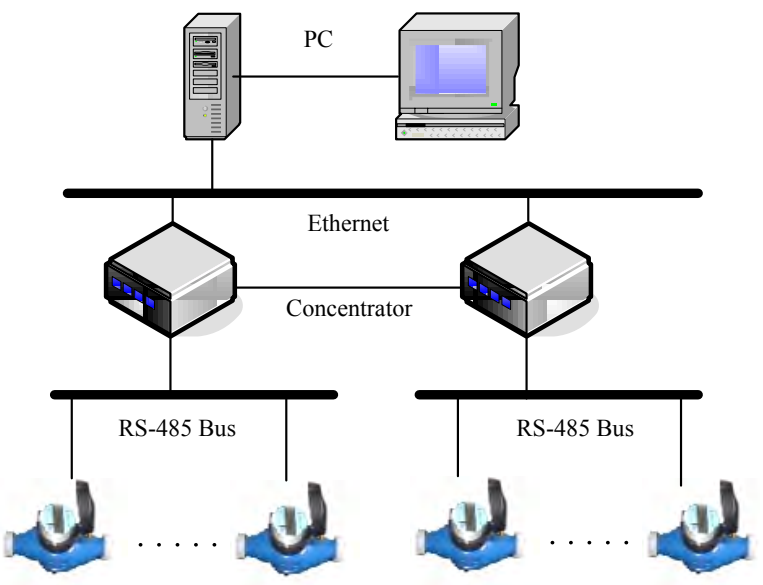

Figure 1. System principal body structure

\section{DESIGN OF THE Host COMPUTER}

\section{A. System Structure}

Host computer management system consists of server software, client side software, data service and database ${ }^{[9]}$, system data flow is shown in Fig .2.

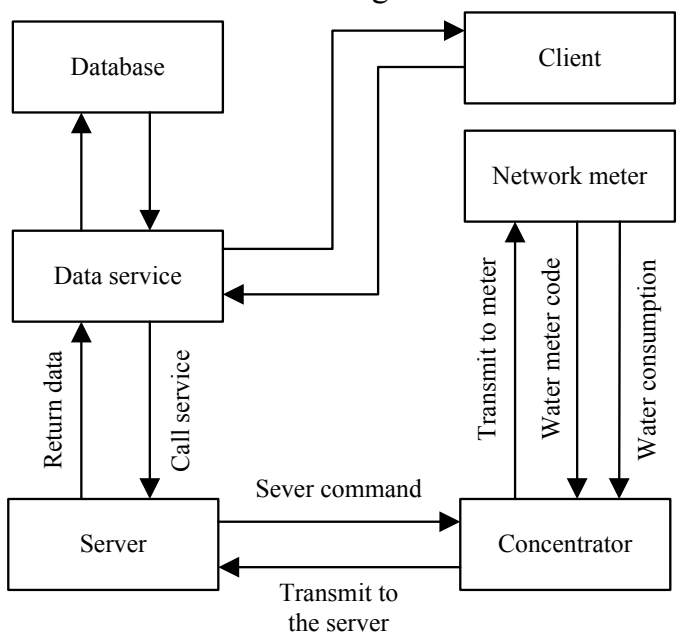

Figure 2. System data flow chart

\section{B. Design of Database}

The system needs store client data, user data, water consuming data and reading time information, so database has corresponding table for each. Store procedures are used to fulfill operations on tables.

TABLE I. T Role TABle TABle Type Styles

\begin{tabular}{cccccc}
\hline $\begin{array}{c}\text { Field } \\
\text { name }\end{array}$ & $\begin{array}{c}\text { Data } \\
\text { type }\end{array}$ & Length & Allow null & $\begin{array}{c}\text { Primary } \\
\text { key }\end{array}$ & Notes \\
\hline Username & varchar & 15 & $\mathrm{~N}$ & $\mathrm{Y}$ & \\
Password & varchar & 15 & $\mathrm{~N}$ & & \\
\hline
\end{tabular}

\begin{tabular}{|c|c|c|c|c|c|}
\hline Field name & Data type & Length & $\begin{array}{l}\text { Allow } \\
\text { null }\end{array}$ & $\begin{array}{l}\text { Primary } \\
\text { key }\end{array}$ & Notes \\
\hline User code & varchar & 30 & $\mathrm{~N}$ & $\mathrm{Y}$ & \\
\hline Name & varchar & 20 & $\mathrm{~N}$ & & \\
\hline Sex & char & 2 & $\mathrm{~N}$ & & \\
\hline ID number & varchar & 18 & $\mathrm{~N}$ & & \\
\hline Phone & varchar & 15 & $\mathrm{~N}$ & & \\
\hline Address & varchar & 50 & $\mathrm{~N}$ & & \\
\hline \multirow[t]{2}{*}{$\begin{array}{c}\text { Water meter } \\
\text { coding }\end{array}$} & varchar & 20 & $\mathrm{Y}$ & & \\
\hline & TABLE III. & \multicolumn{3}{|c|}{ T_WATER TABLE } & \\
\hline Fieldname & $\begin{array}{l}\text { Data } \\
\text { type }\end{array}$ & Length & $\begin{array}{c}\text { Allow } \\
\text { null }\end{array}$ & $\begin{array}{c}\text { Primary } \\
\text { key }\end{array}$ & Notes \\
\hline Number & nchar & 15 & $\mathrm{~N}$ & $\mathrm{Y}$ & \\
\hline $\begin{array}{l}\text { Water meter } \\
\text { coding }\end{array}$ & nchar & 15 & $\mathrm{Y}$ & & \\
\hline $\begin{array}{c}\text { Water } \\
\text { consumption }\end{array}$ & float & 0 & $\mathrm{Y}$ & & \\
\hline \multirow[t]{2}{*}{ Time } & datetime & 0 & $\mathrm{Y}$ & & \\
\hline & TABLE IV. & \multicolumn{3}{|c|}{ T_READ DATA TIME TABLE } & \\
\hline Field name & Data type & Length & $\begin{array}{c}\text { Allow } \\
\text { null }\end{array}$ & $\begin{array}{c}\text { Primary } \\
\text { key }\end{array}$ & Notes \\
\hline Number & varchar & 50 & $\mathrm{~N}$ & $\mathrm{Y}$ & \\
\hline State & tinyint & 0 & $\mathrm{Y}$ & & \\
\hline
\end{tabular}

C. Design of the Server Software

The function of server is mainly keeping connect with concentrator, querying table T_readingTime and checking status value in the table, if status value equals 1 ,meaning meter data should be upload to server; after receiving data, server decodes data and update database data, displays it at user interface.

(1) Design of the Server Software

Server software design process is shown in Fig .3.

(2) Detection module

Detection module process is shown in Fig .4.

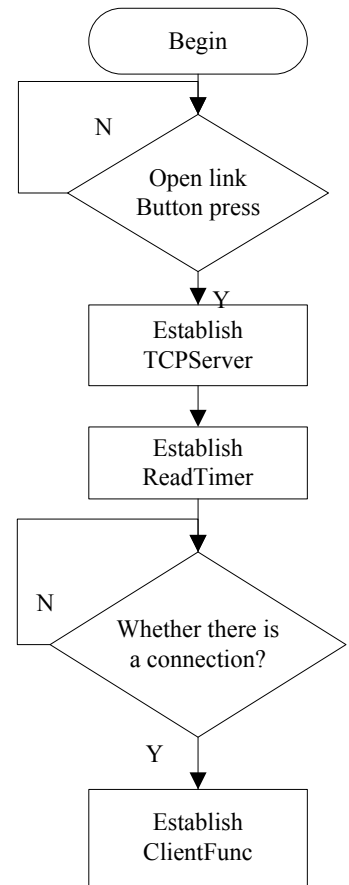

Figure 3. The server soft design process 


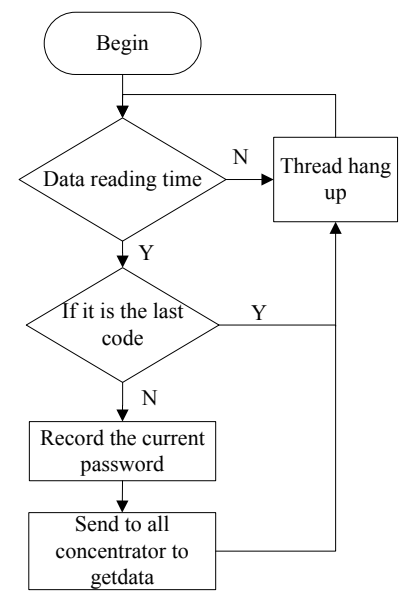

Figure 4 . The detection module flow chart

\section{Design of the Client}

Client side consists of data statistics, customer information management, user management and system settings. Data statistics is achieved based on customer name and time span, customer information module can add customers, delete customers and modify customers information, administrators can change the password through user management. Client Side functional block diagram is shown in Fig .5.

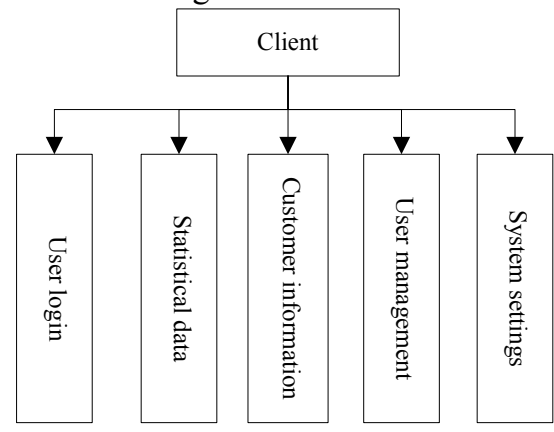

Figure 5. The client function block diagram

\begin{tabular}{|c|c|c|c|c|c|c|}
\hline \multicolumn{2}{|c|}{$\square$ The remote meter reading system } & \multicolumn{4}{|c|}{ 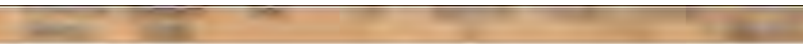 } & 데 回| \\
\hline File(f) Tools(T) & Help(H) & & & & & \\
\hline \multirow{23}{*}{$\begin{array}{l}\text { Statistios } \\
\text { - Customer In } \\
\text { - User manage } \\
\text { (†) System sett. }\end{array}$} & \multicolumn{6}{|c|}{ Statistical data } \\
\hline & Hame: Zhang shuran & - The time from 2014/ 8/ & $8 / 1+$ to $2014 / 8 / 22$. & Summary statistics & O Points Statistics & Query \\
\hline & Name & ID number & Hater meter code & Water consumption & Time & 1 \\
\hline & Zhang shuran & $41302619950310309 \mathrm{x}$ & SR01110208 & 0.67 & $2014 / 8 / 15 \quad 17: 54$ & \\
\hline & Zhang shuran & $41302619950310309 \mathrm{X}$ & SR01110208 & 0.4 & $2014 / 8 / 15 \quad 17: 55$ & \\
\hline & Zhang shur an & $41302619950310309 \mathrm{X}$ & SR01110208 & 2.33 & $2014 / 8 / 15 \quad 17: 55$ & \\
\hline & Zhang shuran & $41302619950310309 \mathrm{X}$ & SR01110208 & 0.49 & $2014 / 8 / 16 \quad 10: 57$ & \\
\hline & Zhang shuran & $41302619950310309 x$ & SR01110208 & 0.89 & 2014/8/16 11:07 & \\
\hline & Zhang shur an & $41302619950310309 \mathrm{x}$ & SR01110208 & 2.08 & 2014/8/16 $11: 08$ & \\
\hline & Zhang shur an & $41302619950310309 \mathrm{X}$ & SR01110208 & 0.88 & $2014 / 8 / 16 \quad 11: 10$ & \\
\hline & Zhang shuran & $41302619950310309 \mathrm{X}$ & SR01110208 & 1. 99 & $2014 / 8 / 16 \quad 11: 11$ & \\
\hline & Thang shuran & $41302619950310309 \mathrm{X}$ & SR01110208 & 0.75 & $2014 / 8 / 16 \quad 16: 27$ & \\
\hline & Zhang shuran & $41302619950310309 \mathrm{~K}$ & SR01110208 & 1.75 & $2014 / 8 / 16 \quad 16: 28$ & \\
\hline & Zhang shur an & $41302619950310309 \mathrm{X}$ & SR01110208 & 0.65 & $2014 / 8 / 16 \quad 16: 29$ & \\
\hline & Zhang shuran & $41302619950310309 \mathrm{X}$ & SR01110208 & 1.61 & $2014 / 8 / 16 \quad 16: 32$ & \\
\hline & Zhang shuran & $41302619950310309 \mathrm{X}$ & SR01110208 & 0.27 & $2014 / 8 / 16 \quad 16: 52$ & \\
\hline & Zhang shur an & $41302619950310309 \mathrm{x}$ & SR01110208 & 2. 13 & $2014 / 8 / 16 \quad 16: 53$ & \\
\hline & Zhang shur an & $41302619950310309 \mathrm{X}$ & SR01110208 & 1.55 & $2014 / 8 / 16 \quad 16: 54$ & \\
\hline & Zhang shuran & $41302619950310309 \mathrm{x}$ & SR01110208 & 1.15 & $2014 / 8 / 20 \quad 19: 38$ & \\
\hline & Zhang shuran & $41302619950310309 \mathrm{X}$ & SR01110208 & 0.86 & $2014 / 8 / 228: 51$ & \\
\hline & Zhang shuran & $41302619950310309 \mathrm{X}$ & SR01110208 & 2. 37 & $2014 / 8 / 228: 55$ & \\
\hline & Zhang shuran & $41302619950310309 \mathrm{X}$ & SR01110208 & 1. 93 & $2014 / 8 / 228: 57$ & $\equiv$ \\
\hline & Zhang shuran & $41302619950310309 \mathrm{X}$ & SR01110208 & 2. 09 & 2014/8/22 9:03 & \\
\hline - पIII & & & & & & - \\
\hline
\end{tabular}

Figure 6. Data statistics

Users can query all customers' water usage information, then only the total statistical query, when come to individual customer, the usage information can be queried totally or partially, User interface is shown in Fig .6.

\section{CONCENTRATOR DESIGN}

\section{A. The Block Diagram of Concentrator System}

Concentrator based on ARM9 and Linux operation system $^{[10,11]}$, consists of Ethernet, serial communications, reset circuit, power supply module and so on. Concentrator system block diagram shown in Fig .7.

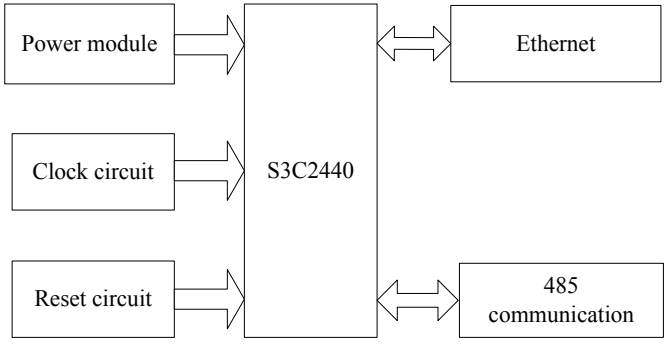

Figure 7. The block diagram of concentrator System

\section{B. System Concentrator Software Design}

In software design, Linux multithreading, Socket communication, serial communication, file manipulation techniques are involved. The total of four sub-systems of 
threads, and their function is to read data, write data via network, read data and write data via serial ports. When the program starts, it reads Sr.llz file, the file will be encoded into a single link list in order to communicate to the meter later. In Ubuntu10.04 generates an ARM executable program by arm-linux-gcc, then the program will be ported to ARM, added to the startup items, the program can automatically start at boot time. Program flow chart is shown in Fig .8.

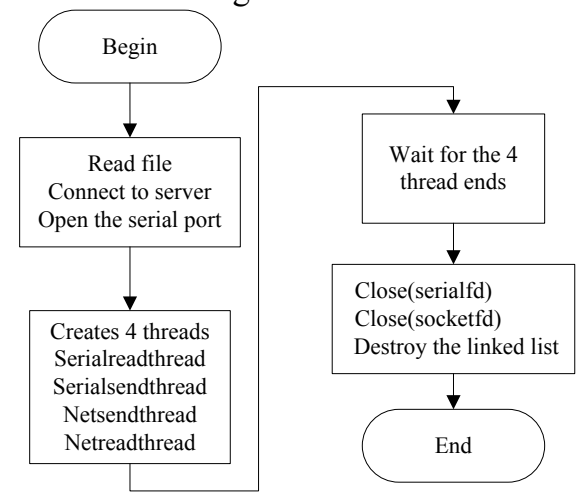

Figure 8 . The concentrator design process

\section{THE NetWork WATER Meter Design}

Network Water Meter is based on SCM, the main functions is reading the pulse via SCM, then make analysis and calculation, converting into water dosage, showing it in the $12864 \mathrm{LCD}$, and storing it in the AT24C16, when the data upload command is received, uploading data by 485 bus to concentrator which then upload it to host computer via Ethernet. Meter block diagram shown in Fig . 9.

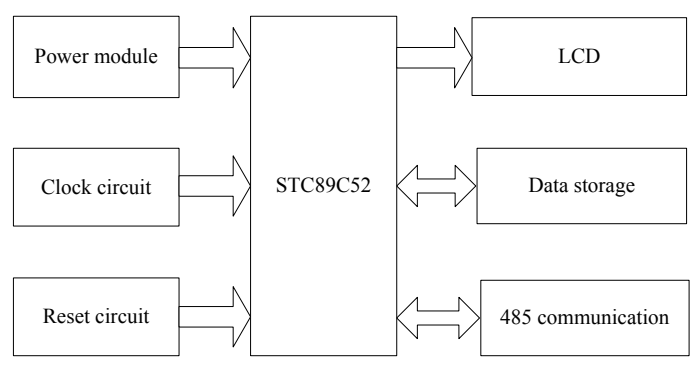

Figure 9. The water meter block diagram

\section{A. Water Flow Acquisition Module}

In the water meter acquisition module, the water flow sensor is the core. Water flow sensor is mainly made of a plastic body, the flow of the rotor assembly and the Hall sensor. Using USN-HS21TB Hall flow sensor in this water meter and the sensor is calculated as Eq.1.

$$
\mathrm{F}(\mathrm{Hz})=8.1 * \text { flow rate }(\mathrm{Q})-6(\mathrm{l} / \mathrm{min}) \mathrm{Q}=\mathrm{L} / \mathrm{Min}
$$

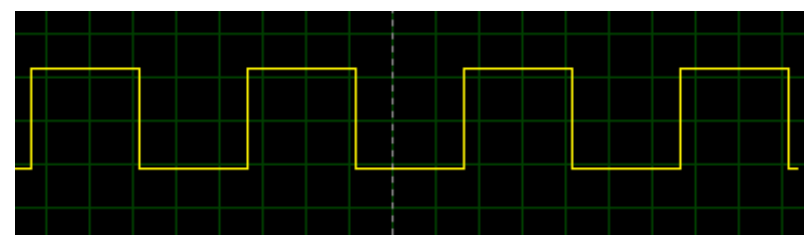

Figure 10. The square-wave pulse
The water flow sensor mounted inlet side to detect water flow, when the flow of water through the rotor assembly, magnetic rotor and speed changes as the flow rate changes, the Hall sensor output corresponding square wave pulse signal back to the controller, which determines the dosage of the water flow, calculate the actual water consumption. Square wave pulse signal is shown in Fig .10.

\section{B. Software Design}

The design of water meter software adopts the modular programming, which is shown in Fig .14.

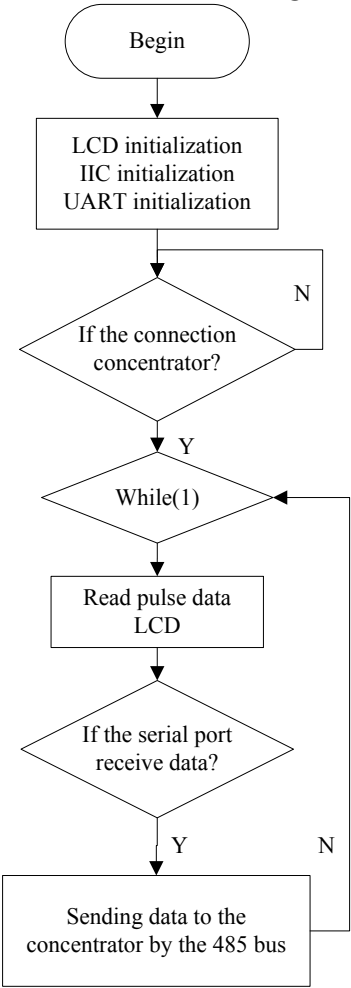

Figure 14. The flow chart of water meter software design

\section{Design Testing Analysis of System}

When the server task starting, it will set up task execution cycle, that cycle of reading the meter data and the server reads the database. If it needs to read the water meter data, then sends commands to connect concentrators. After concentrators receives GETDATA commands, sends reading meter coding to each meter in single linked list, if consistent with its own code, meter send meter data to the concentrator through 485 bus, concentrator then send data to the server. Throughout the test, the meter data is sent to server between $0-9$.

\section{Testing Results}

(1)The water meter received code from the concentrator.

(2) Concentrator receives the GETDATA command, and sends code to water meter, receive water meter data.

(3)The server read the database, sends GETDATA to the concentrator, receiving area displays the received data, and updates the database through analysis.

(4) The part of the client reads the database and observes the updated results of water yield. 


\section{CONCLUSION}

This paper describes a design to develop a remote centralized reading meter system which combined software and hardware using 485 bus and Ethernet as data transmit media. Server can send read command to each concentrator via Ethernet, concentrator then send command to each water meter, water meter sent meter data to the concentrator through 485 bus after receiving the command, and then the concentrator upload data via Ethernet to the server. Client side can view and control consumers' water meters. The various functions of the system basically completed, but there are some needs further improvement. Concentrator program is a terminal program, the next step to complete the interface design and realize using other database as data store. Even if the server fails or is turned off, the data can be saved in time. It will reads the data in concentrator database when the server is turned on.

\section{ACKNOWLEDGMENT}

This work was supported in part by the science and technology research project of education department of Henan Province (14A510009), the funding scheme for youth teacher of Henan Province (2012GGJS-191), the science and technology key project of Henan Province (142102210568, 142102210063).

\section{REFERENCES}

[1] Z. J. Zhang, Y. Li, and W. Q. Yuan, "Meter character recognition method based on gray template matching," Proceedings of the 29th Chinese Control Conference, Beijing, China, 2010.
[2] C. S. Fredrick1, "Smart water metering networks an intelligent investment," Water and Wastewater International, vol. 26, pp. 16-19, 2011.

[3] M. M. Al-Rawahi, Z. Nabeel, and M. Ahmed, "A multisensory intelligent device for real-time multiphase flow metering in oi fields," IEEE Transactions on Instrumentation and Measurement, vol. 59, pp. 1507-1519, 2010.

[4] R. Gomes, A. S. Marques, and J. Sousa, "Decision support system to divide a large network into suitable District Metered Areas," Water Science and Technology, vol. 65, pp. 1667-1675, 2012.

[5] J. J. Li, J. J. Cui, and L. L. Jiang, "Design and implementation of distributed remote-reading water meter monitoring system based on SaaS,". Lecture Notes in Electrical Engineering, vol. 107, pp. 413-420, 2012.

[6] N. Wu, Y. J. Guo, Y. Q. Wei, "Design of the remote wireless meter reading system based on GPRS," TelkomnikaIndonesian Journal of Electrical Engineering, vol. 11, pp. 63586366, 2013.

[7] S. R. Mounce, J. B. Boxall, and J. Machell, "Development and verification of an online artificial intelligence system for detection of bursts and other abnormal flows," Journal of Water Resources Planning and Management, vol. 136, pp. 309318, 2011.

[8] C.Wang, "The design of the data acquisition mode of wireless intelligent remote water meter system in the high-rise building," 2011 International Conference on Control, Automation and Systems Engineering, Singapore, 2011.

[9] J. M. Li, Paradigm Development of SQL Server. Tsinghua University Press, 2010.

[10] L. G. Zhou, The ARM Embedded Foundation Course. Beijing, Beijing university of aeronautics and astronautics press, 2008.

[11] M. Young, The Technical Writer's Handbook. Mill Valley, CA University 